\title{
ZnO Nanowire Formation by Two-Step Deposition Method Using Energy-Controlled Hollow-Type Magnetron RF Plasma
}

\author{
Hideki Ono and Satoru Iizuka \\ Department of Electrical Engineering, Graduate School of Engineering, Tohoku University, Miyagi, Sendai 980-8579, Japan \\ Correspondence should be addressed to Satoru Iizuka, iizuka@ecei.tohoku.ac.jp
}

Received 14 June 2011; Accepted 16 September 2011

Academic Editor: Renzhi Ma

Copyright ( $) 2011 \mathrm{H}$. Ono and S. Iizuka. This is an open access article distributed under the Creative Commons Attribution License, which permits unrestricted use, distribution, and reproduction in any medium, provided the original work is properly cited.

$\mathrm{ZnO}$ nanowire was produced in RF (radio frequency) discharge plasma. We employed here a two-step deposition technique. In the 1st step, zinc atoms were sputtered from a zinc target to create zinc nuclei on a substrate before the growth of $\mathrm{ZnO}$ nanostructure. Here, we used pure argon plasma for physical sputtering. In the 2nd step, we employed an oxygen discharge mixed with argon, where oxygen radicals reacted with zinc nuclei to form $\mathrm{ZnO}$ nanostructures. Experimental parameters such as gas flow ratio and target bias voltage were controlled in $\mathrm{O}_{2} /$ Ar plasma. Properties of the depositions were analysed by SEM and Raman spectroscopy. We found that many folded and bundled nanowires formed in the 2 nd step. The diameter of wires was typically $10-100 \mathrm{~nm}$. We also discussed a growth mechanism of $\mathrm{ZnO}$ nanowires.

\section{Introduction}

$\mathrm{ZnO}$ is an oxide semiconductor with a wide band gap of $3.37 \mathrm{eV}$ at room temperature and has a large exciton binding energy of $60 \mathrm{meV}$ in comparison with $\mathrm{GaN}$ [1-3]. Therefore, $\mathrm{ZnO}$ was expected to develop a light emitting device, especially for a blue-light emission diode, instead of GaN.

$\mathrm{ZnO}$ nanostructures such as nanowires and nanorods are expected to make nanophotonic devices [4]. $\mathrm{ZnO}$ nanowires and nanorods have been believed to grow via vapour-liquidsolid (VLS) process $[5,6]$. However, several other techniques for the growth have been reported. For example, molecular beam epitaxy (MBE) and pulsed-laser deposition (PLD) are generally employed for the growth processes of $\mathrm{ZnO}$ thin layers. These techniques take an advantage for the formation of high-quality $\mathrm{ZnO}$ crystals. Metal organic chemical vapour deposition (MOCVD) process is also one of the remarkable processes nowadays $[7,8]$.

Here, the growth process of $\mathrm{ZnO}$ by a plasma processing was studied. This is superior to the other processes for lowtemperature and large-area deposition. Moreover, when we control the energy of plasma, we would make $\mathrm{ZnO}$ thin films or $\mathrm{ZnO}$ nanoparticle, selectively. However, very few studies referred to the energy-controlled plasma.

In this study, we investigated how zinc, sputtered from a zinc target, reacted with oxygen in $\mathrm{O}_{2} / \mathrm{Ar}$ plasma when discharge parameters such as gas pressure, gas flow ratio, and target bias voltage were changed. We employed a two-step deposition technique for the formation of $\mathrm{ZnO}$ nanostructures. In the 1st step, zinc atoms were sputtered from a zinc target to create zinc nuclei for the base of $\mathrm{ZnO}$ nanostructure growth. Here, we used pure argon plasma for physical sputtering. In the 2nd step, we employed an oxygen discharge with argon, where oxygen radical reacted with zinc nuclei on a substrate to form $\mathrm{ZnO}$ nanosuructures. Dependence on the deposition time was investigated in $\mathrm{O}_{2} /$ Ar plasma.

\section{Experimental Setup}

Experimental apparatus $[9,10]$ is schematically shown in Figure 1. Plasma was generated by a hollow-type magnetron (HTM) RF plasma source at frequency of $13.56 \mathrm{MHz}[11$, 12]. The HTM consists of powered electrode made of stainless cylinder of $4.8 \mathrm{~cm}$ in diameter and $5.5 \mathrm{~cm}$ height, 


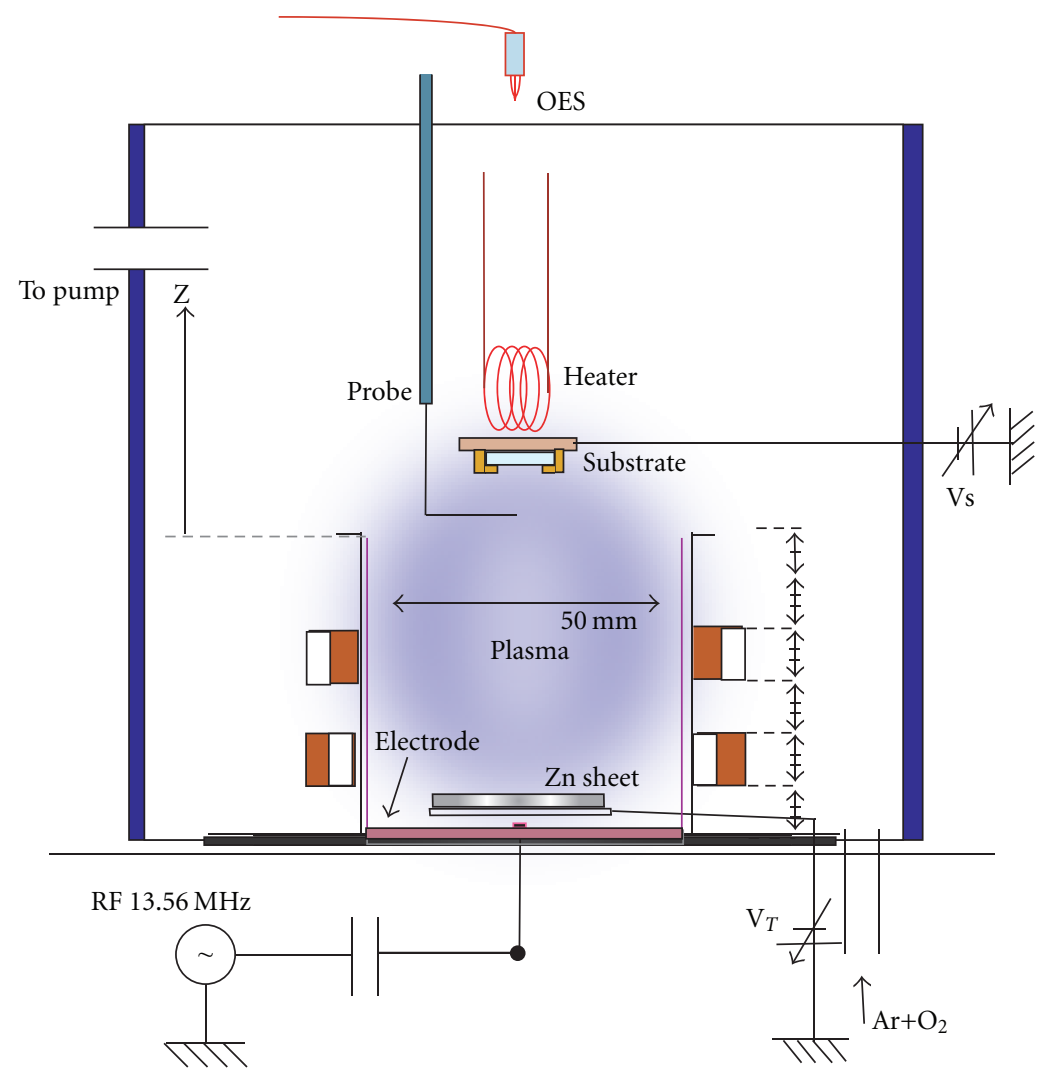

FIgURE 1: Experimental apparatus.

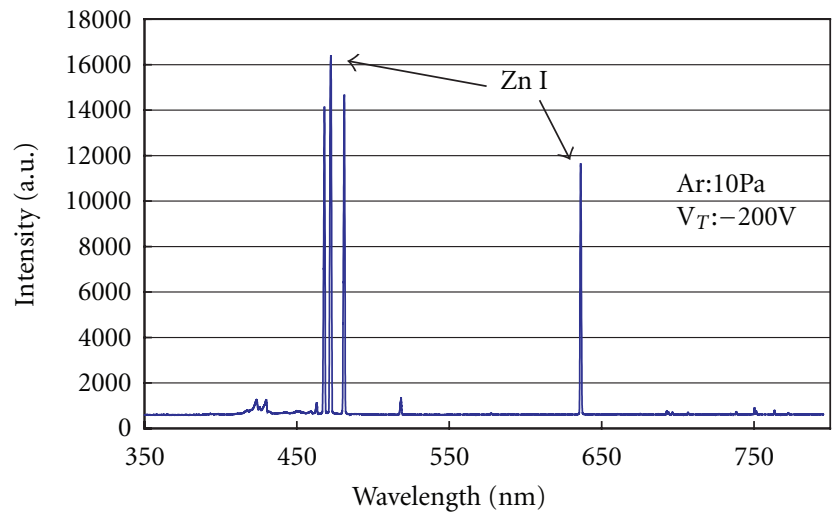

Figure 2: Typical optical emission spectrum.

which is covered by a grounded stainless steel cylinder of $5.2 \mathrm{~cm}$ diameter and $6.0 \mathrm{~cm}$ height. Furthermore, two magnet rings are wound around outside of a grounded cylinder with spacing of $2 \mathrm{~cm}$ to confine the plasma and to prevent the electrode from sputtering by deep self-bias voltage.

A zinc target was set on a bottom plate. Target DC bias voltage $V_{\mathrm{T}}$ controlled the $\mathrm{Zn}$ sputtering. We can change gas pressure ratio $\mathrm{O}_{2} / \mathrm{Ar}$ and target $\mathrm{DC}$ voltage $V_{\mathrm{T}}$. In this experiment a grid used for the electron temperature control was removed. Plasma parameters were measured by a Langmuir probe. Wavelength of optical emission from the

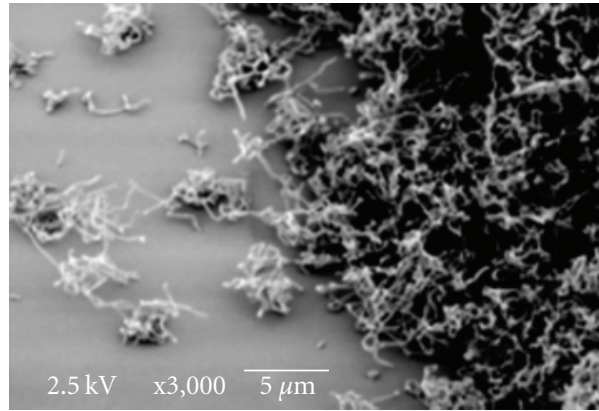

Figure 3: Typical SEM image of nanowires.

plasma was measured by a spectroscope (OES). Substrate was fixed at $2.5 \mathrm{~cm}$ above the top of the electrode. Deposition of $\mathrm{ZnO}$ on the substrate was estimated by scanning electron microscope (SEM) and Raman spectroscope.

\section{Experimental Results}

3.1. Growth of $\mathrm{ZnO}$ Nanowires. Blue-light emission from $\mathrm{Zn}$ neutrals produced in the plasma was found to be one of the most important factors for a deposition of $\mathrm{ZnO}$ nanowires. Typical spectrum of the optical emission is shown in Figure 2. The spectrum can be characterized by a strong blue emission line of zinc neutral around $460 \mathrm{~nm}$. However, the blue-light emission diminished drastically when $\mathrm{O}_{2}$ gas 


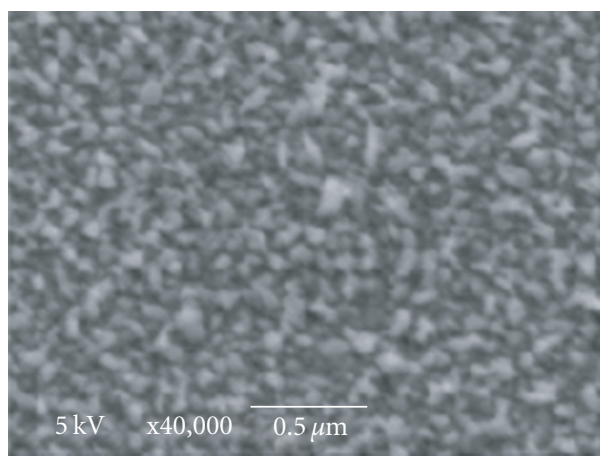

(a)

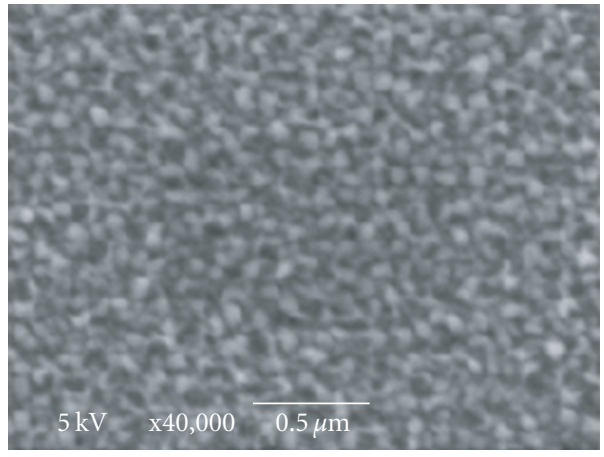

(c)

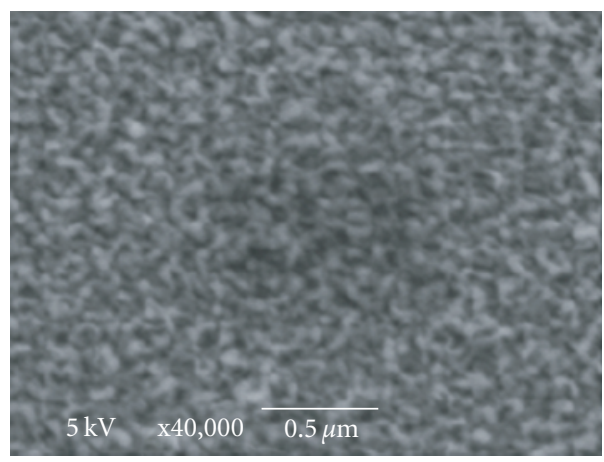

(b)

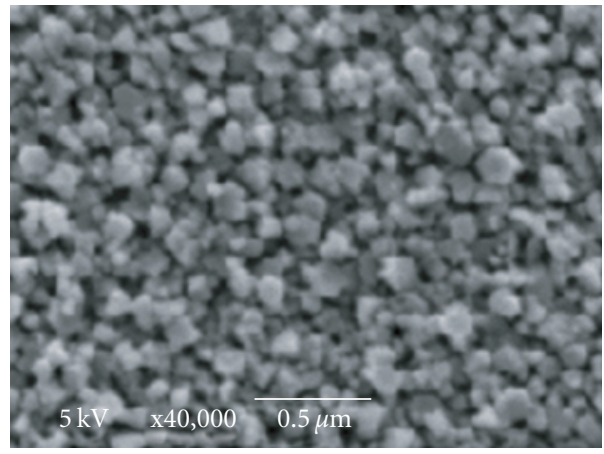

(d)

Figure 4: SEM images with deposition time $T_{\mathrm{ZnO}}$ as a parameter in case of $T_{\mathrm{Zn}}=60 \mathrm{~s}: T_{\mathrm{ZnO}}=$ (a) $0 \mathrm{~s}$, (b) $60 \mathrm{~s}$, (c) $300 \mathrm{~s}$, and (d) $600 \mathrm{~s}$.

was slightly mixed with Ar. This phenomenon markedly influenced $\mathrm{ZnO}$ deposition. In case of weak blue-light emission, we could not detect materials consisting of $\mathrm{ZnO}$ nanowires on the substrate.

In case of simultaneous processing with $\mathrm{Zn}$ sputtering and its oxidization by using a mixed gas of $\mathrm{O}_{2}$ and Ar, we clearly observed a formation of nanowires. After turning on the plasma with blue-light emission, the substrate was inserted into the plasma for the deposition of $\mathrm{ZnO}$. Deposition period was varied in a range 10-600 sec. Typical SEM image of the materials deposited under strong bluelight emission is shown in Figure 3. We found many folded nanowires bundled on the substrate. The diameter of wires was of the order of $100 \mathrm{~nm}$. From Raman spectroscopy, we found that these wires consisted of $\mathrm{ZnO}$.

Almost all nanowires were bent and twisted complicatedly as shown in Figure 3. The structure was in principle one dimensional, but the shape was complicated, which might be preferably available for an increment of effective surface area of $\mathrm{ZnO}$ materials. Total surface area could be much larger than that of flat and smooth $\mathrm{ZnO}$ surface. However, from a viewpoint of practical application in industries, it would be better for these nanowires to grow straight in one direction on the substrate. One-dimensionally grown nanowires will make it easy to produce an electronic device like PN junction for blue-light emission. Therefore, we intended to investigate the mechanism by which nanowires were bundled on the substrate. In order to clarify the growth process the deposition period was varied under various conditions.
3.2. Dependence on Deposition Time. We tried first to examine initial growth process of $\mathrm{ZnO}$ nanowires. From a comparison with Raman spectrum, we confirmed that $\mathrm{Zn}$ stacked up first on the substrate to form thin $\mathrm{Zn}$ layer, then oxygen reacted with zinc to construct nanowires. Thickness of $\mathrm{Zn}$ layer was an important factor for $\mathrm{ZnO}$ nanowire growth. If $\mathrm{Zn}$ layer was too thin, for example, we could not obtain nanowires. Even when oxygen reacted with $\mathrm{Zn}$, the reaction could not result in construction of nanowires. So, next we tried to find out a dependence of the growth of $\mathrm{ZnO}$ nanowires on the thickness of $\mathrm{Zn}$ layer deposited initially.

Therefore, for this reason, we separated processing procedures, that is, $\mathrm{Zn}$ deposition process and its oxidization process. So, the deposition period $T_{\mathrm{Zn}}$ for $\mathrm{Zn}$ layer formation was separated from the period $T_{\mathrm{ZnO}}$ for oxygen reaction. We can control reaction time of oxygen, independently. Then, we would find a mechanism of the growth of $\mathrm{ZnO}$ nanowires.

In the experiments we fixed RF power at $100 \mathrm{~W}$ and substrate temperature at $150^{\circ} \mathrm{C}$. In the deposition period of $\mathrm{Zn}$ layer (1st period) Ar gas pressure was fixed at $10 \mathrm{~Pa}$. No oxygen gas was fed in, and the target bias voltage was fixed at $-200 \mathrm{~V}$ for zinc sputtering. In the oxygen reaction period (2nd period), however, Ar gas pressure was fixed at $9.5 \mathrm{~Pa}$ under fixed $\mathrm{O}_{2}$ gas pressure at $0.5 \mathrm{~Pa}$. No target bias voltage was applied in this case. The 1st period $T_{\mathrm{Zn}}$ was varied in a range of 5-600 sec, and the 2 nd period $T_{\mathrm{ZnO}}$ was varied in a range of $0-600 \mathrm{sec}$.

When the deposition period of $\mathrm{Zn}$ is short $\left(T_{\mathrm{Zn}}=60 \mathrm{~s}\right)$, thin film including only $\mathrm{Zn}$ was generated on the substrate, instead of $\mathrm{ZnO}$ nanowires. Figure 4(a) shows a typical SEM 


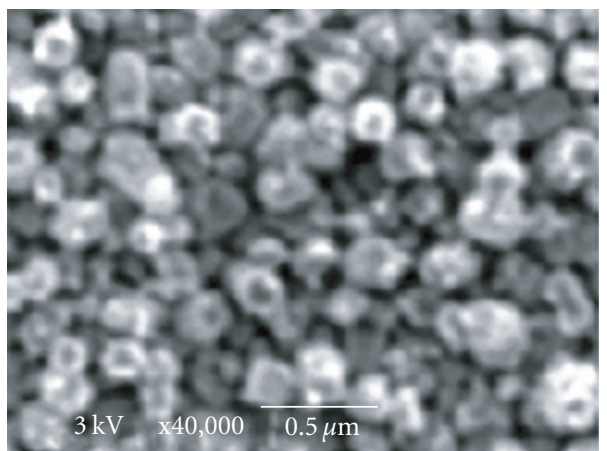

(a)

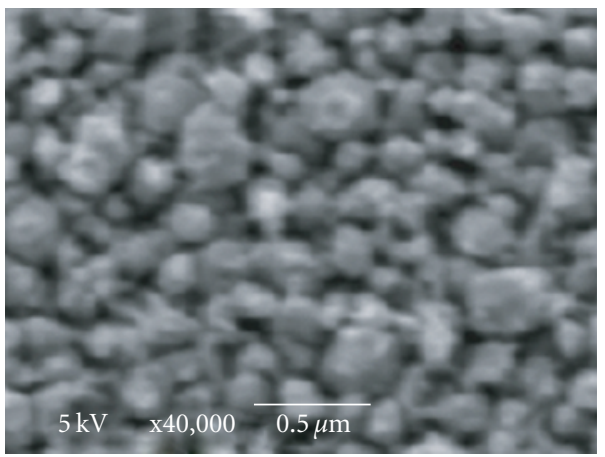

(c)

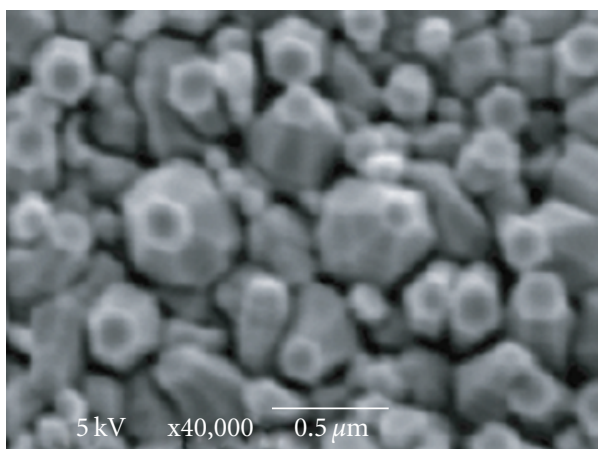

(b)

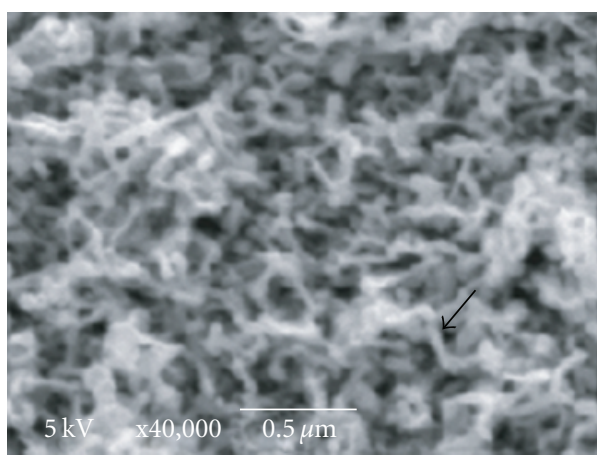

(d)

Figure 5: SEM images with deposition time $T_{\mathrm{ZnO}}$ as a parameter in case of $T_{\mathrm{Zn}}=300 \mathrm{~s}: T_{\mathrm{ZnO}}=$ (a) $0 \mathrm{~s}$, (b) $30 \mathrm{~s}$, (c) $60 \mathrm{~s}$, and (d) $90 \mathrm{~s}$. The nanowire is pointed by arrow in (d).

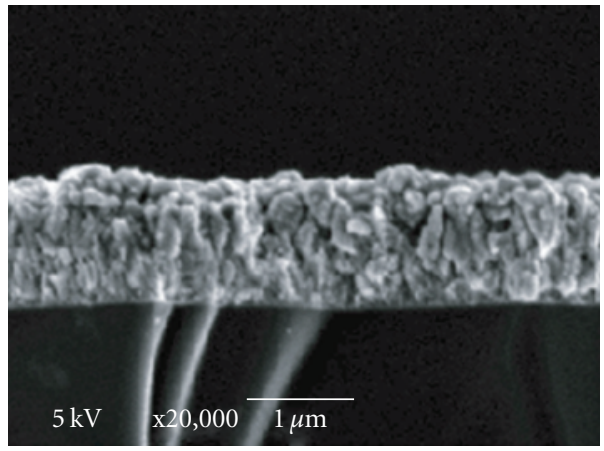

(a)

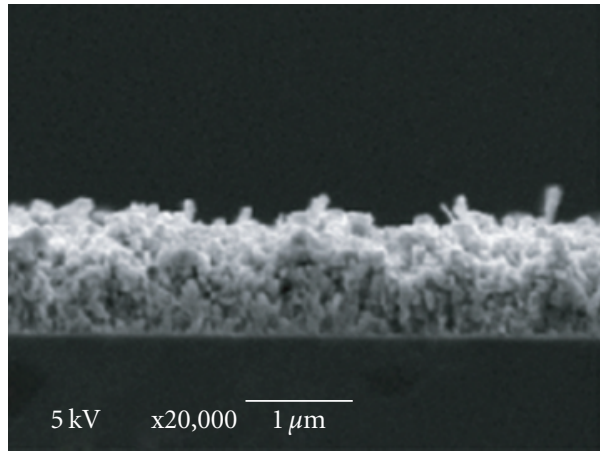

(c)

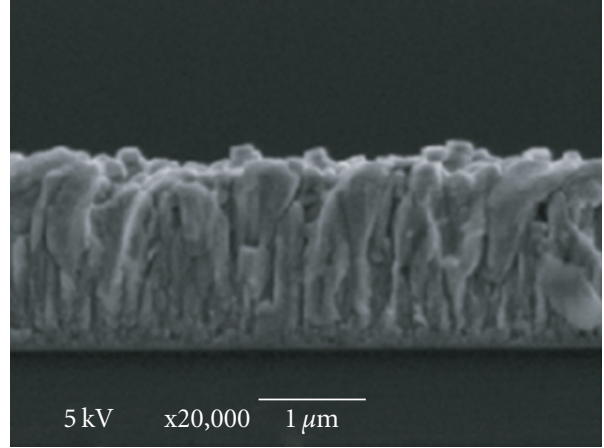

(b)

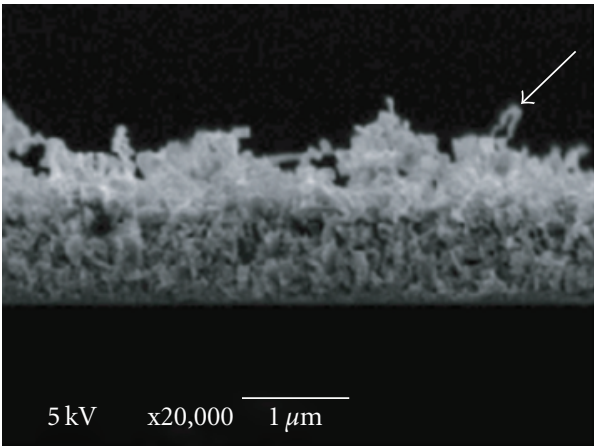

(d)

FIGURE 6: SEM images of cross-section with deposition time $T_{\mathrm{ZnO}}$ as a parameter in case of $T_{\mathrm{Zn}}=300 \mathrm{~s}: T_{\mathrm{ZnO}}=$ (a) $0 \mathrm{~s}$, (b) $30 \mathrm{~s}$, (c) $60 \mathrm{~s}$, and (d) $90 \mathrm{~s}$. The nanowire is pointed by arrow in (d). 


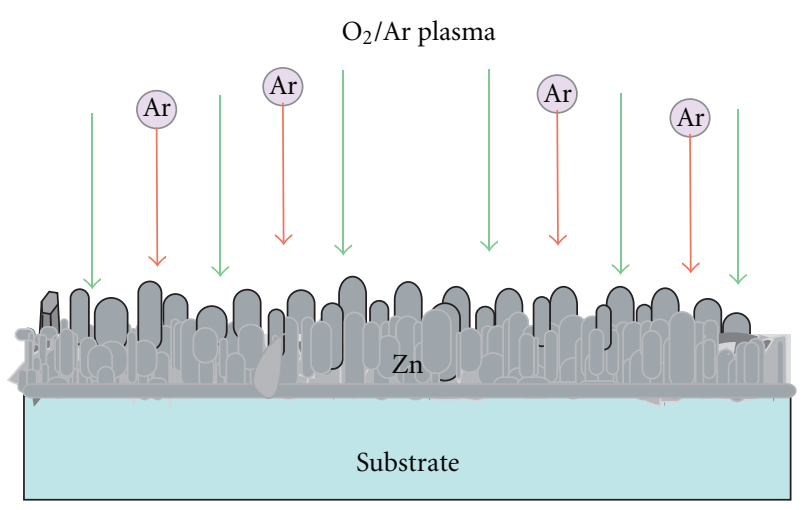

(a)

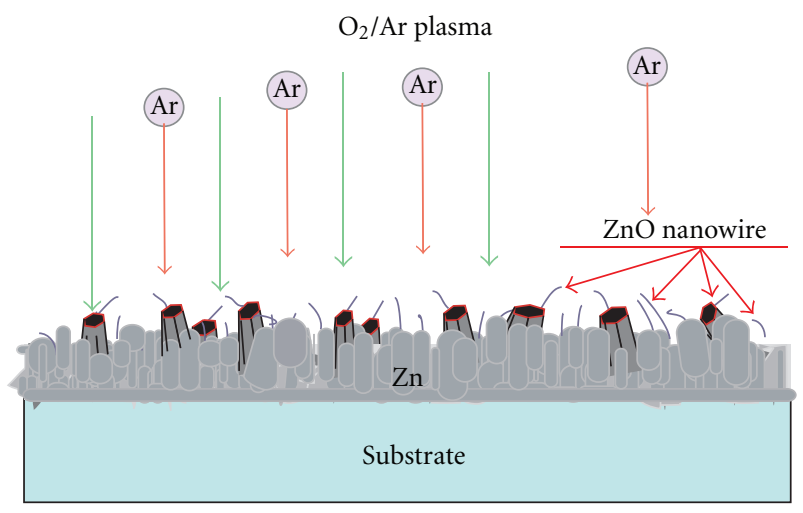

(c)

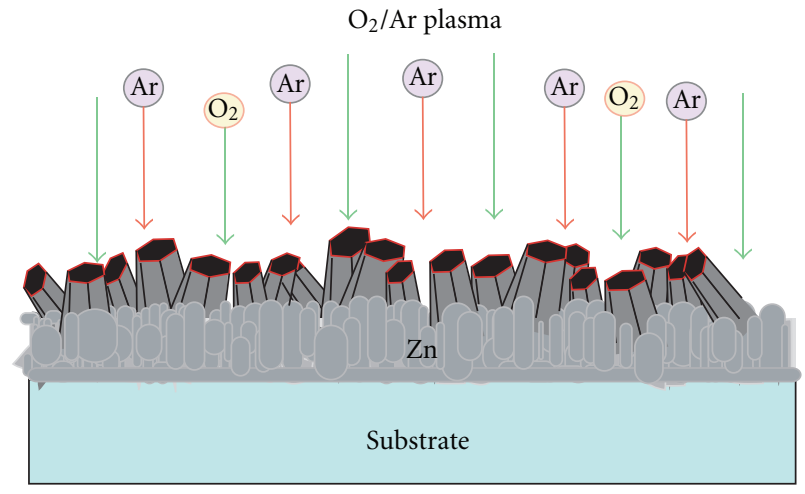

(b)

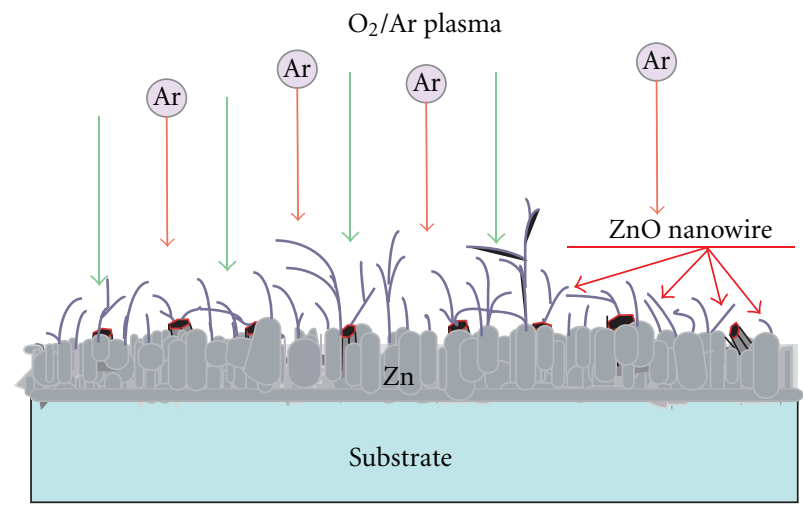

(d)

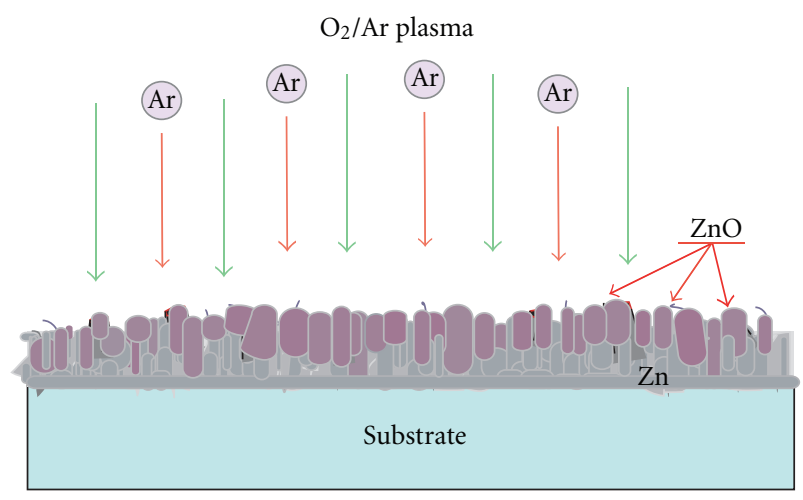

(e)

FIGURE 7: Growth model of $\mathrm{ZnO}$ nanowires in case of Figure 5. (a) Irregular surface of Zn layer with particulate and pillar-like structures is formed in the 1st step. (b) Particulate and pillar-like structures are changed to hexagonal pillars, growing with time, by oxidization in the 2 nd step. (c) Then, the hexagonal pillars start shrinking by Ar ion sputtering, which triggers a start of $\mathrm{ZnO}$ nanowire growth. (d) ZnO nanowires grow and bend in the presence of Ar ion bombardment. (e) The nanowire growth stops and decays with time by the ion sputtering, and finally smooth surface of $\mathrm{ZnO}$ layer comes out.

image taken from the top of the substrate after deposition period of $T_{\mathrm{Zn}}=60 \mathrm{~s}$. From a detailed observation, we confirmed that the layer consisted of many small-size zinc particles. The size was $50-100 \mathrm{~nm}$, and the particles were distributed almost randomly on the surface.

In the 2nd period we introduced oxygen to oxidize the surface of $\mathrm{Zn}$ particles and oxygen reaction period $T_{\mathrm{ZnO}}$ was varied. Then, thin layer including $\mathrm{ZnO}$ was generated on the top of $\mathrm{Zn}$ particles, as shown in Figures $4(\mathrm{~b})$ and 4(c), where we found many small pillows. After oxidization period of $600 \mathrm{~s}$, that is, $T_{\mathrm{ZnO}}=600 \mathrm{~s}$, many pillars changed their shape to something like hexagon pillars, as shown in Figure 4(d). These pillars grew in time and were distributed on the surface of the substrate. These pillars seem to grow from the bottom of the deposited Zn particles. The hexagonal structure indicates that these were consisting of $\mathrm{ZnO}$ crystal [13]. Increasing oxidization period the shape of hexagon structure gradually disappeared, and more smooth structure 


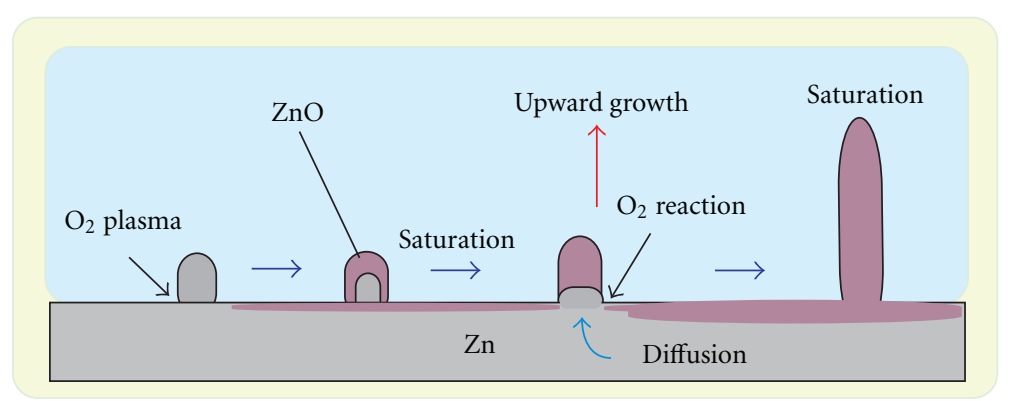

FIGURE 8: Growth model of $\mathrm{ZnO}$ nanowires, corresponding to the phase (c) in Figure 7. Zn pillar of small size, formed initially on $\mathrm{Zn}$ thin film, is oxidized from its surface. Crystallization of $\mathrm{ZnO}$ occurs first at the tip of the pillar, and excess oxygen extracts $\mathrm{Zn}$ from the $\mathrm{Zn}$ layer. Then, $\mathrm{ZnO}$ nanowire extends upward, being accompanied with the $\mathrm{Zn}$ supply from the $\mathrm{Zn}$ layer. Finally, the growth of $\mathrm{ZnO}$ nanowire is completed because of a limit of $\mathrm{Zn}$ diffusion from the $\mathrm{Zn}$ layer.

came out, eventually. The size was also gradually decreased by the effect of Ar sputtering. We could not observe nanowire formation in this case.

We have checked similar oxidization in case of $T_{\mathrm{Zn}}=$ 300 s. Figure 5 shows SEM images for the case of $T_{\mathrm{Zn}}=$ 300 s. As shown in Figure 5(a), we clearly found many pillars after the deposition of $\mathrm{Zn}$ layer. The pillars grew in length and in diameter, and the cross-section of the top turned to a hexagonal structure as shown in Figure 5(b). However, then, the shape was gradually changed and more smaller hexagon pillars were generated as shown in Figure 5(c). The size was decreased to about $50-100 \mathrm{~nm}$ and the shape was changed to something like a pillar again. Then, finally, further oxidization caused an evolution of thin nanowires, growing from the dwindled hexagon pillars, as shown by the arrow in Figure 5(d). We find clearly characteristic structures of $\mathrm{ZnO}$ nanowires, though the hexagon pillars shrink simultaneously by the effect of oxidization and Ar sputtering. The condition for the growth of nanowires seemed to correspond to a production of smaller size structure like shrunken hexagon pillows.

Since no additional $\mathrm{Zn}$ was supplied from the plasma, the growth of nanowires came to an end finally. Therefore, the diameter of wires remained thin compared with that in Figure 3. After further oxidization such nanowires were almost completely removed by Ar sputtering and only homogeneous thin film of $\mathrm{ZnO}$ was left instead of the nanowires.

Figure 6 shows cross sectional view of deposited layers in case of $T_{\mathrm{Zn}}=300 \mathrm{~s}$. The growth of nanowires was found in Figures 6(c) and 6(d). In case of initial growth, most of the wires looked straight as one-dimensional needles, as shown in Figure 6(c). However, the direction of the growth was quite random because of an irregularity of the background zinc layers. With increasing the length, the wires had a tendency to bend, as shown by the arrow in Figure 6(d). This might be due to a stoichiometric unbalance between $\mathrm{Zn}$ and $\mathrm{O}$. Therefore, the crystallization was not enough in this growth phase.

\section{Discussion}

Formation process of $\mathrm{ZnO}$ nanowires was studied by using two-step deposition technique. The growth processes were schematically shown in Figure 7. In the 1st step, only $\mathrm{Zn}$ layers were deposited as shown in Figure 7(a). The shape of $\mathrm{Zn}$ layer was something like particulates and pillars. In the 2nd period, though no additional zinc was supplied on the substrate, growth of $\mathrm{ZnO}$ nanowires took place. This means that oxygen could be taken into $\mathrm{Zn}$ layer to provide oxidization layer near the surface.

The shape of deposited zinc surface was changed to hexagonal pillar, which had grown in time, as shown in Figure $7(\mathrm{~b})$. In this case the pillars might consist of crystallized $\mathrm{ZnO}$. The shape of this structure was straight with no bending component. We could not observe nanowires at this moment. The beginning time of nanowire growth seemed to be related with the initial size of hexagonal pillars. Though $\mathrm{ZnO}$ pillars grew first, they finally shrunk due to Ar sputtering. So, the size of pillars diminished in time (Figure 7(c)). The start point of nanowire growth was related with this timing. As the size was reduced, the growth of $\mathrm{ZnO}$ nanowires started as shown in Figures $7(\mathrm{c})$ and $7(\mathrm{~d})$. However, after further oxidization, the nanowire growth stopped and decayed in time. Finally, such nanowires were almost completely removed by Ar sputtering and smooth surface of $\mathrm{ZnO}$ layer came out (Figure 7(e)).

As another important mechanism, it should be pointed out that a supply of $\mathrm{Zn}$ took place from the bottom of nanowires. Ar ions impinging on the substrate could heat $\mathrm{Zn}$ surface to provide a liquid-solid state, in which $\mathrm{Zn}$ atoms could move and react with oxygen to form the structure of $\mathrm{ZnO}$. Therefore, the growth point of $\mathrm{ZnO}$ should be the bottom end of nanowires as shown in Figure 8. Zn pillar of small size, formed initially on $\mathrm{Zn}$ thin film, was oxidized from its surface. Therefore, $\mathrm{ZnO}$ crystallization started first at the tip of the pillar. Since $\mathrm{Zn}$ could be supplied from the $\mathrm{Zn}$ layer to the region of excess oxygen, the crystallized part of $\mathrm{ZnO}$ extended upward as a form of nanowire, being accompanied with diffusion of $\mathrm{Zn}$ from the $\mathrm{Zn}$ layer. Finally, the growth of $\mathrm{ZnO}$ nanowire would be completed because of a limit of $\mathrm{Zn}$ diffusion. Initial zinc layer played as a kind of catalysis, which promoted not only the growth of $\mathrm{ZnO}$ hexagonal pillars but also the growth of $\mathrm{ZnO}$ nanowires. Two-step growth technique is quite important for investigating and controlling the growth of $\mathrm{ZnO}$ nanostructures. 
In case of one-step growth by using a mixed gas of $\mathrm{O}_{2}$ and Ar, typical spectrum of Raman shifts revealed that the intensity of $\mathrm{ZnO}$ signal clearly increased with deposition time. However, before and even during the growth of $\mathrm{ZnO}$, we always observed another peak at $540 \mathrm{~cm}^{-1}$, which always appeared in case of zinc deposition. This indicated that supply of $\mathrm{Zn}$ atom on the substrate dominated the supply of oxygen for $\mathrm{ZnO}$ production. In other words, the amount of oxygen radicals $\mathrm{O}^{*}$ might be lacked relatively. For this reason, nanowires contained not only $\mathrm{ZnO}$ component but also metallic $\mathrm{Zn}$. The reason why the wires were bending would come from an irregularity in one-dimensional growth of $\mathrm{ZnO}$ crystal because of excess $\mathrm{Zn}$ supply during the growth.

\section{Conclusions}

Here, we employed a two-step deposition method for the formation of $\mathrm{ZnO}$ nanostructures. We separated the zinc deposition from its oxidization process, that is, the deposition period $T_{\mathrm{Zn}}$ for $\mathrm{Zn}$ layer formation was separated from the period $T_{\mathrm{ZnO}}$ for oxygen reaction. This method makes it possible to control the time of oxygen reaction.

By separating the period of $\mathrm{ZnO}$ nanowire formation from the period of $\mathrm{Zn}$ layer formation, we found $\mathrm{ZnO}$ nanowires grown in the 2nd step in $\mathrm{O}_{2} / \mathrm{Ar}$ RF plasma. We found also that the size of $\mathrm{Zn}$ pillars formed in the 1st step was crucial for the nucleation and growth of $\mathrm{ZnO}$ nanowires in the 2nd step. A formation model of $\mathrm{ZnO}$ nanowires was proposed. We also observed a formation of thin homogeneous $\mathrm{ZnO}$ film, as a result of further oxidization, accompanied with Ar sputtering. The method proposed here would be useful for understanding the growth mechanism of $\mathrm{ZnO}$ nanostructures.

\section{Acknowledgment}

The work was supported by a Grant-in-Aid for Scientific Research from the Ministry of Education, Culture, Sports, Science and Technology, Japan.

\section{References}

[1] K. Hüemmer, "Interband magnetoreflection of ZnO," Physica Status Solidi B, vol. 56, no. 1, pp. 249-260, 1973.

[2] A. Ohtomo, K. Tamura, M. Kawasaki et al., "Roomtemperature stimulated emission of excitons in $\mathrm{ZnO} /(\mathrm{Mg}$, Zn)O superlattices," Applied Physics Letters, vol. 77, no. 14, Article ID 2204, 3 pages, 2000.

[3] M. H. Huang, Y. Wu, H. Feick, N. Tran, E. Weber, and P. Yang, "Catalytic growth of zinc oxide nanowires by vapor transport," Advanced Materials, vol. 13, no. 2, pp. 113-116, 2001.

[4] F. Patolsky, G. Zheng, and C. M. Lieber, "Nanowire sensors for medicine and the life sciences," Nanomedicine, vol. 1, no. 1, pp. 51-65, 2006.

[5] R. S. Wagner and W. C. Ellis, "Vapor-liquid-solid mechanism of single crystal growth," Applied Physics Letters, vol. 4, no. 5, pp. 89-90, 1964.

[6] A. M. Morales and C. M. Lieber, "A laser ablation method for the synthesis of crystalline semiconductor nanowires," Science, vol. 279, no. 5348, pp. 208-211, 1998.
[7] X. Liu, X. Wu, H. Cao, and R. P. H. Chang, "Growth mechanism and properties of $\mathrm{ZnO}$ nanorods synthesized by plasma-enhanced chemical vapor deposition," Journal of Applied Physics, vol. 95, no. 6, pp. 3141-3147, 2004.

[8] S. Choopun, H. Tabata, and T. Kawai, "Self-assembly $\mathrm{ZnO}$ nanorods by pulsed laser deposition under argon atmosphere," Journal of Crystal Growth, vol. 274, no. 1-2, pp. 167$172,2005$.

[9] H. Ono and S. Iizuka, "Growth of $\mathrm{ZnO}$ nanowires in hollowtype magnetron $\mathrm{O}_{2}$ /Ar RF plasma," Thin Solid Films, vol. 518, no. 3, pp. 1016-1019, 2009.

[10] K. Kumeta, H. Ono, and S. Iizuka, "Formation of $\mathrm{ZnO}$ nanostructures in energy-controlled hollow-type magnetron RF plasma," Thin Solid Films, vol. 518, no. 13, pp. 3522-3525, 2010.

[11] J. Emi, K. Kato, T. Abe, and S. Iizuka, "Formation of nanoparticles by control of electron temperature in hollowtyped magnetron radio frequency $\mathrm{CH}_{4} / \mathrm{H}_{2}$ plasma," Japanese Journal of Applied Physics, vol. 45, no. 10, pp. 8071-8074, 2006.

[12] J. Emi and S. Iizuka, "Characteristics of carbon-related materials deposited in electron-energy controlled $\mathrm{CH}_{4} / \mathrm{H}_{2} \mathrm{RF}$ discharge plasmas," Diamond and Related Materials, vol. 20, no. 4, pp. 568-572, 2011.

[13] K. Prabakar and H. Kim, "Growth control of $\mathrm{ZnO}$ nanorod density by sol-gel method," Thin Solid Films, vol. 518, no. 24, pp. e136-e138, 2010. 

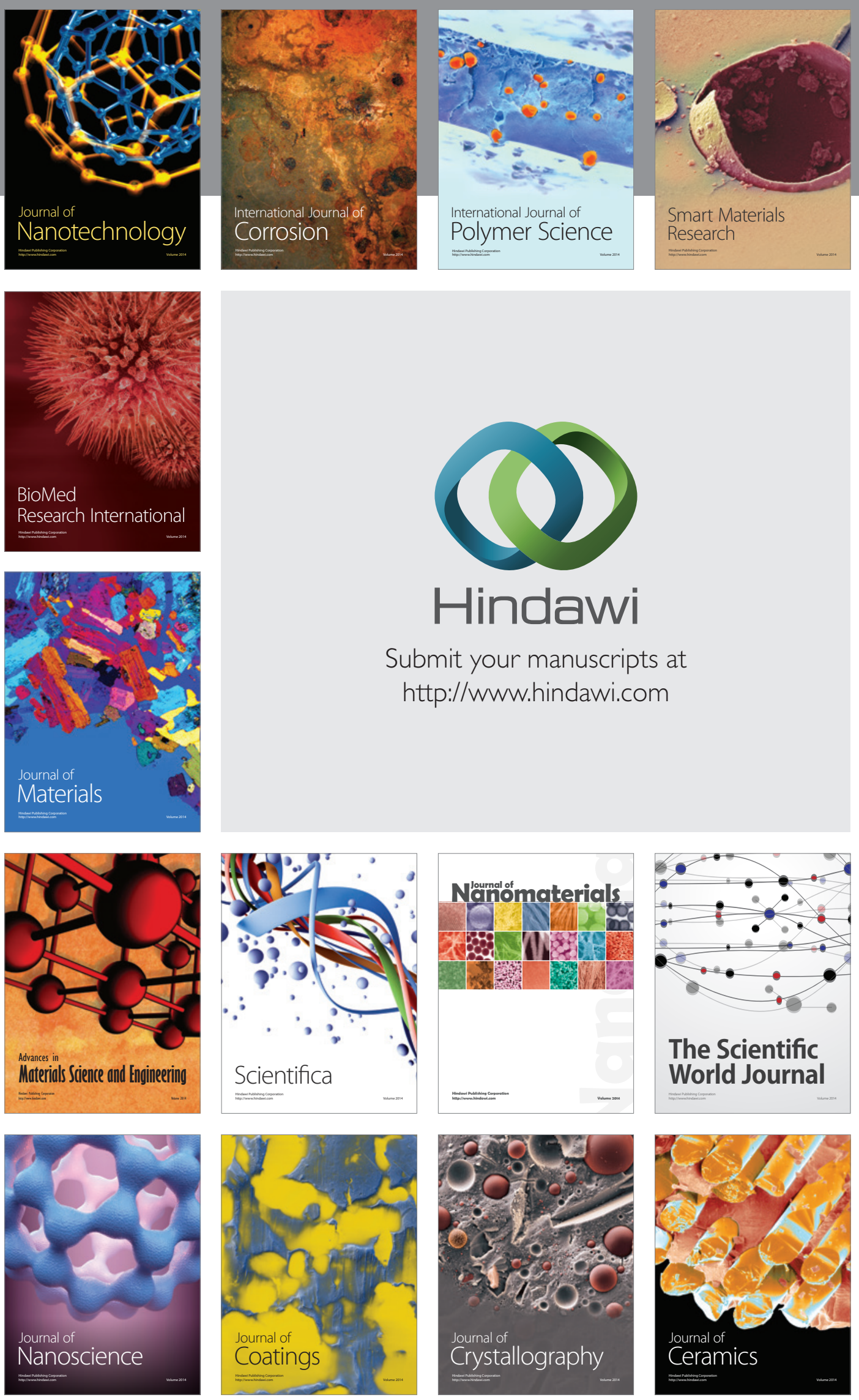

The Scientific World Journal

Submit your manuscripts at

http://www.hindawi.com

\section{World Journal}

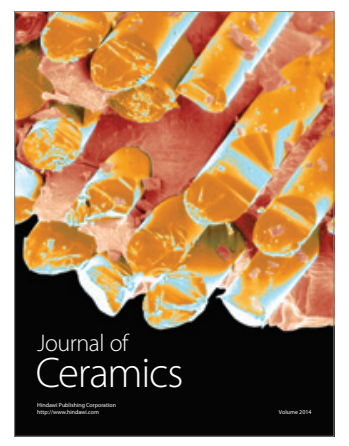

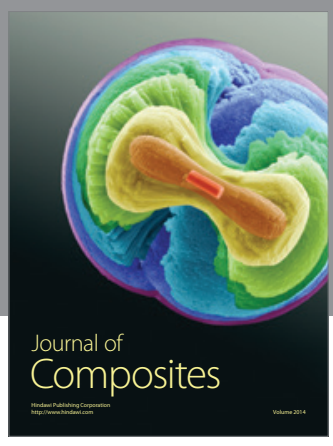
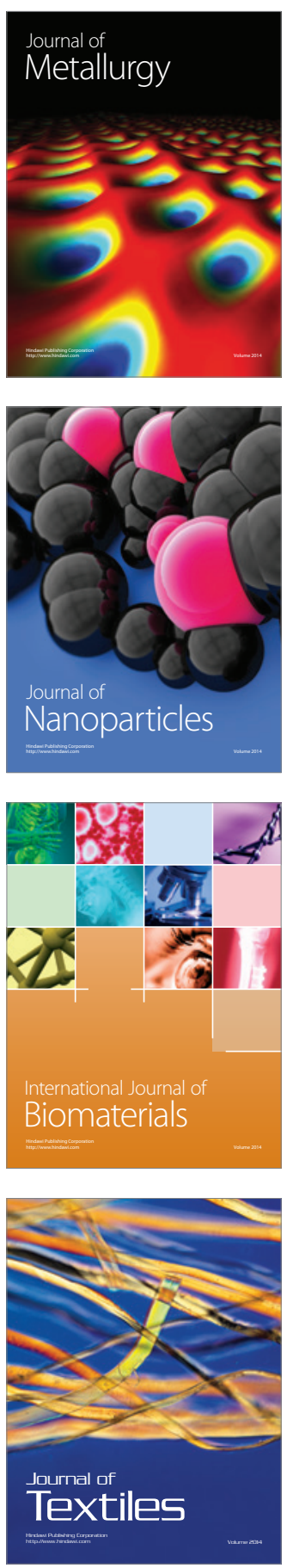